Article

\title{
Seed Germination in Relation to Total Sugar and Starch in Endosperm Mutant of Sweet Corn Genotypes
}

\author{
Potchanee Pairochteerakul ${ }^{1}$, Darunee Jothityangkoon ${ }^{1}$, Danupol Ketthaisong ${ }^{2,3}$, \\ Sakunkan Simla ${ }^{4}$, Kamol Lertrat ${ }^{3}$ and Bhalang Suriharn $1,3, *$ (D) \\ 1 Department of Agronomy, Khon Kaen University, Khon Kaen 40002, Thailand; \\ potchanee824@gmail.com (P.P.); djothit@gmail.com (D.J.) \\ 2 Department of Horticulture, Khon Kaen University, Khon Kaen 40002, Thailand; danuket@kku.ac.th \\ 3 Plant Breeding Research Center for Sustainable Agriculture, Khon Kaen University, Khon Kaen 40002, \\ Thailand; kamo19@gmail.com \\ 4 Department of Agricultural Technology, Mahasarakham University, Mahasarakham 44150, Thailand; \\ sakunkans@gmail.com \\ * Correspondence: sphala@kku.ac.th; Tel.: +66-43-202-696
}

Received: 2 November 2018; Accepted: 5 December 2018; Published: 9 December 2018

\begin{abstract}
The use of combinations of two or more genes controlling carbohydrate characters of corn is an attractive way to improve table quality of sweet corn. Poor seed quality of the inbred lines hinders the progress of this strategy for hybrid seed production. The objective of this study was to evaluate sweet corn inbred lines with combinations of double and triple recessive genes for germination percentage, seed vigor, total sugar content, and starch content. Eleven sweet corn genotypes including seven inbred lines $\left(\mathrm{F}_{6}\right.$ generation) with different combinations of genes controlling carbohydrate characters and four $\mathrm{F}_{1}$ hybrids were used. The germination experiment was conducted under standard test between papers (BP) and accelerated aging (AA) test. The data were recorded for germination percentage, germination speed, normal and abnormal seedling, seedling length, and seedling dry weight. The seeds were analyzed for total sugar and starch content in endosperm at maturity stage. The results showed that single recessive genotype (sh2sh2) had high germination percentage and seedling vigor. The combinations of $b t$ or sh2 gene with $w x$ gene resulted in low germination percentage and poor seedling vigor. However, combinations of triple recessive genes (btbt sh2sh2 wxwx) had good germination in BP test but they performed poorly in AA test.
\end{abstract}

Keywords: seed germination; seed vigor; starch granule; sucrose content; gene combination

\section{Introduction}

Sweet corn is an important vegetable crop cultivated extensively in the tropical and temperate region of the world. It has been developed through breeding to create new commercial hybrids for a century [1]. Traditional sweet corn has the sugary gene (su1), which has been grown for decades, but the sucrose in the endosperm is changed to starch very rapidly after harvest at the fresh stage. Super sweet corn carries the shrunken gene (sh2) or brittle gene (bt2) and each type has two to three times higher sucrose than sul and torpidly converts sucrose into starch in the kernel [2]. Sugary enhancer corn has the se gene, which increases sugar in the endosperm and this gene also increases the tenderness of the kernel.

These types of sweet corn have recessive genes that increase sugar in endosperm and improve table quality of vegetable corn. However, the problems of super sweet corn hybrid especially for high-quality varieties (sh2, bt2 and se) are poor seed germination, poor seed vigor and poor stand establishment [3], 
resulting in lower yields, variable ear size and variable maturity [4]. The corn varieties with $b t$, su1 and normal field corn (dominant alleles of $B t, S u 1$, and Sh2) have better seed germination and seed vigor than the corn varieties with sh2 under both laboratory and field conditions [3]. Poor seed quality of this type of corn is due to small endosperm, small embryo, high sugar and low starch in endosperm that make the corn susceptible to fungal and soilborne pathogens [5]. Application of chemical and seed treatment have been examined to increase seed quality. Fungicide seed treatment is an effective method to improve seed emergence of sh2 sweet corn [6]. Many seed priming methods have been proposed for improving seed germination of sweet corn [7].

The use of combinations of two genes with synergistic effect for seed quality has been suggested to improve seed germination and quality of sweet corn. The combination of su1su1 Sh2sh2 is commonly used for hybrid seed production and the combinations of Su1su1 sh2sh2 or su1su1 Se1se1 are used in the temperate area. The modified hybrid with the combination of su1su1 Sh2sh2 has good germination similar to that with su1 and the hybrid has $25 \%$ of $s h 2$ kernels in the ear [8]. The genotypes with combination of su1su1 Se1se1 have better eating quality than the genotypes with normal sugary (su1), and they also have better emergence and earlier vigor than the genotypes with normal sugary enhancer (se1se1) for cool areas [9]. The concept of combinations of two or more genes can be used to improve the eating quality of waxy corn [10] especially in Asia. Sweet waxy corn hybrid (Sh2sh2 wxwx or Btbt $w x w x)$ has $75 \%$ of sticky kernels ( $w x)$ and $25 \%$ of sweet kernels (sh 2 or $b t$ ) in the same ear.

The combination of three recessive genes can improve table quality of sweet corn [8]. The cross of su1su1 se1se1 Sh 2 Sh $2 \times$ su1su 1 Se1Se1 sh2sh 2 could increase sugar level in the $\mathrm{F}_{2}$ generation [8]. The hybrids with combination of su1, se1 and sh 2 had 1.5 to 3.0 times the sugar level of the higher than the hybrids with normal su1 [11]. However, the main problem of hybrid seed production is to first develop parental lines with combinations of double recessive genes such as su1su1 sh2sh2, su1su1 se1se1, sh2sh $2 w x w x$, and $b t b t w x w x$, and these parental lines has poor seed quality. The inbred lines with combination of double recessive genes ( $b t$ and sh2) in $w x$ background had total sugar almost two times higher than sugary and waxy corn genotypes [12].

The previous studies so far have reported the combinations of two recessive genes. In order to improve the quality of waxy corn genotypes by increasing the sweet kernels in waxy corn ear, it is important to study seed germination and chemical compositions of sweet corn inbred lines with triple recessive genes. However, this information is still lacking in the literature. In this study, the commercial varieties of supersweet corn with good genetic background for seed germination and seed vigor are used to develop a base population and select the corn progenies with combinations of double and triple genes by using conventional method and marker assisted selection to generate homozygous progenies. The objective of this study was to evaluate seed germination, seed vigor, total sugar content and starch content of sweet corn inbred lines with combinations of double and triple recessive genes. The information obtained in this study is the continuation of the project to fill the gap of knowledge on seed quality of these corn inbred lines. The purpose is to develop new $F_{1}$-hybrid corn varieties with the premium table quality and the production technologies that are associated with the seeds.

\section{Materials and Methods}

\subsection{Plant Materials}

Seven sweet corn inbred lines ( $\mathrm{F}_{6}$ generation) with different combinations of genes controlling endosperm characters and four $\mathrm{F}_{1}$ hybrids were used in this study (Table 1). D8 has triple genes (btbt shsh 2 wxwx). D22, C4, and B52 have double genes (btbt ShSh2 wxwx, BtBt shsh2 wxwx, and btbt shsh2 $W x W x$, respectively). These inbred lines were developed from two parental lines (101bt and TSC) by using conventional method with marker-assisted selection by using six SSR primers (p-bnlg1182, p-umc1964, p-umc1953, p-phi061, and p-phi022 from [13]) at Khon Kaen University, Thailand in 2014-2017. 101bt is an inbred line (btbt ShSh2 wxwx) from Khon Kaen University and TSC F 1 hybrid (BtBt sh2sh2 WxWx) is a temperate super sweet corn from USA. The two inbred lines (Su75/TSC and 
90 H3/TSC) and two $F_{1}$ hybrids (Su75 and H3 from Syngenta and Pacific Seed Company, respectively) have genotypes with recessive alleles sh2 (BtBt shsh2 $W x W x$ ). KGW1 is a sweet waxy corn hybrid (Btbt $\operatorname{ShSh} 2 w x w x)$ from Khon Kaen University. A base population was developed from $\mathrm{F}_{2}$ generation and only shrunk seeds were selected for planting in the next generations (Figure 1). SSR markers were used to selected double and triple recessive gene combinations at seeding stage (15 days after planting).

Table 1. Corn inbred lines/varieties were used in this study

\begin{tabular}{cccc}
\hline Lines/Hybrids & Types & Genotypes & Phenotypes \\
\hline 1. D8 & Inbred line; Triple recessive genes & $b t b t \operatorname{shsh} 2 w x w x$ & shrunken \\
2. D22 & Inbred line; Double recessive genes & $b t b t \operatorname{ShSh} 2 w x w x$ & shrunken \\
3. C4 & Inbred line; Double recessive genes & $B t B t \operatorname{shsh} 2 w x w x$ & shrunken \\
4. B52 & Inbred line; Double recessive genes & $b t b t \operatorname{shsh} 2 W x W x$ & shrunken \\
5. Su75/TSC & Inbred line; Single recessive gene & $B t B t \operatorname{shsh} 2 W x W x$ & shrunken \\
6. H3/TSC & Inbred line; Single recessive gene & $B t B t \operatorname{shsh} W x W x$ & shrunken \\
7. Su75 & $\mathrm{F}_{1}$ hybrid & $B t B t \operatorname{shsh} 2 W x W x$ & shrunken \\
8. H3 & $\mathrm{F}_{1}$ hybrid & $B t B t \operatorname{shsh} 2 W x W x$ & shrunken \\
9. TSC & $\mathrm{F}_{1}$ hybrid & $B t B t \operatorname{shsh} W x W x$ & shrunken \\
10. 101bt & Inbred line & $b t b t \operatorname{ShSh} 2 w x w x$ & shrunken \\
11. KGW1 & $\mathrm{F}_{1}$ hybrid & $B t b t \operatorname{ShSh} 2 w x w x$ & flint \\
\hline
\end{tabular}

(a)

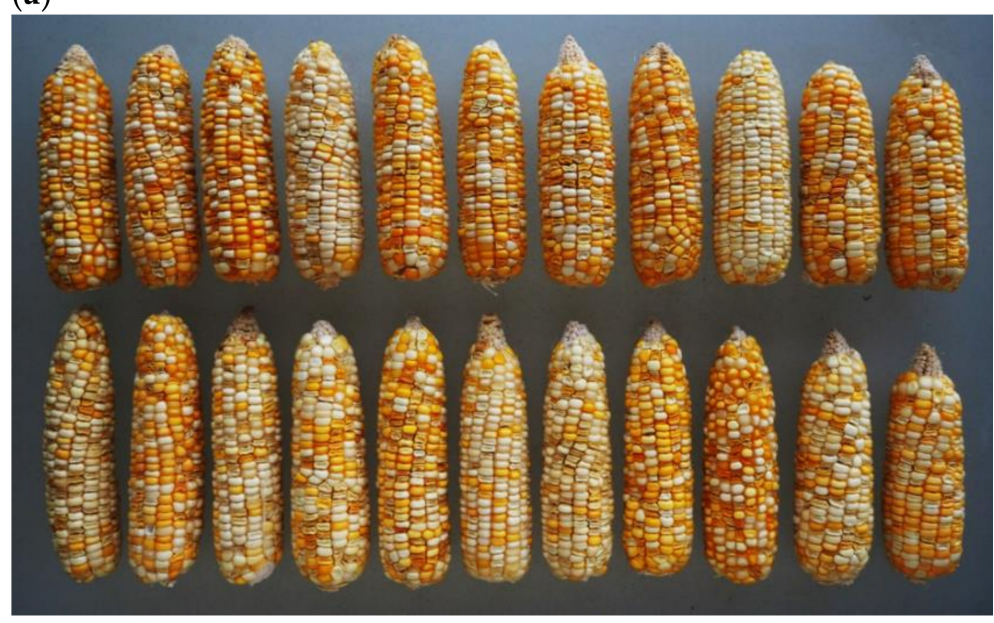

(b)

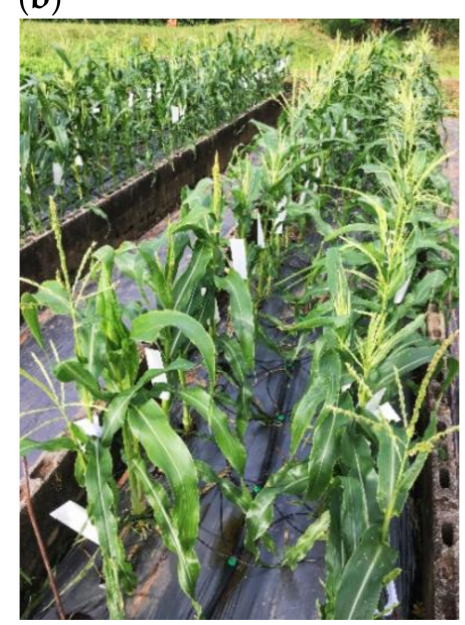

Figure 1. (a)The ears of the $F_{2}$ population used for development of sweet corn inbred lines and (b) plants of some sweet corn genotypes in crossing nursery.

\subsection{Laboratory Experiment}

\subsubsection{Seed Quality}

Germination standard test between papers (BP) was used to measure seed germination at $25^{\circ} \mathrm{C}$ for seven days, seed growth rate and speed of germination and the accelerated aging test (AA) at $42{ }^{\circ} \mathrm{C}$ for $96 \mathrm{~h}$ was used to determine seed vigor. The eleven treatments were laid out in a completely randomized design (CRD) with three replications of 50 seeds each. The seeds were placed on the moist sheet (paper towels) with pedicels oriented in the same direction, covered with another moist sheet, rolled up and placed in a germination chamber (Economic Delux, ECDC1E, SNIJDERS, Codogno (LO), Italy). These sheets were moisturized with tap-water without sterilization. The number of normal and abnormal seedling was recorded at 7 days after sowing for seed germination. Then, the seedling dry weight was determined from all normal seeding and the average seedling dry weight was calculated [14]. 
The speed of germination (SG) was calculated from the number of germinated seedlings at the first-day after sowing and kept counting every day until final count, when all the seeds germinated. The following formula is used to calculate the speed of germination (SG):

$$
\mathrm{SG}=\frac{\text { No. of normal seedling }}{\mathrm{d} \text { of } 1^{\text {st }} \text { count }}+\ldots+\frac{\text { No. of normal seedling }}{\mathrm{d} \text { of final count }}
$$

\subsubsection{Dry Weight of Seed Parts}

Dry weighs of seed parts were determined for all seed parts. Three replications of 10 seeds for

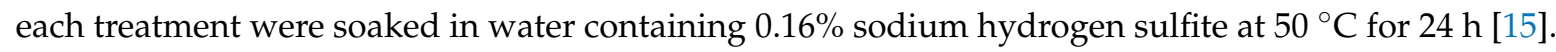
Whole seed was separated into embryo, endosperm, and pericarp and then dried at $70{ }^{\circ} \mathrm{C}$ for $48 \mathrm{~h}$. The weights of dry seed parts were expressed as $\mathrm{mg} / \mathrm{seed}$ and total seed percentage.

\subsubsection{Chemical Analyses}

The total starch contents of corn seeds for each genotype were determined by using the method described previously [15]. Native starches were isolated by using $100 \mathrm{~g}$ of each sample with three replications. To inactivate the enzymes, the samples of each treatment were soaked in $0.16 \%$ sodium hydrogen sulfite at $50{ }^{\circ} \mathrm{C}$ for $24 \mathrm{~h}$, ground in the blender and passed through a $105 \mu \mathrm{m}$ sieve. The slurry ground samples were put in touene alcohol to seperate native starches and dried at $80{ }^{\circ} \mathrm{C}$ for $24 \mathrm{~h}$. To extract total starch, the samples of the $50 \mathrm{mg}$ of native starch powder were extracted by $80 \%$ ethanol and boiled in water bath at $80^{\circ} \mathrm{C}$ for $1 \mathrm{~h}$. The samples were then analyzed by using a spectrophotometer followed by phenolic-sulfuric method and measured at $490 \mathrm{~nm}$.

Total sugar contents were analyzed by using phenol-sulfuric method [16]. The samples were ground in a blender and ground slurry samples were passed through a $63 \mu \mathrm{m}$ sieve. Then samples of $50 \mathrm{mg}$ were put into glass tubes with $3 \mathrm{~mL}$ of $80 \%$ ethanol and boiled in the water bath $65^{\circ} \mathrm{C}$ for $1 \mathrm{~h}$ to extract sugar contents from ground slurry samples. The samples were further transferred to new glass tubes containing ethanol and the process was repeated two times. The ethanol solutions of nine $\mathrm{mL}$ at final extraction were analyzed using the phenol-sulfuric method and measured at $490 \mathrm{~nm}$ with a spectrophotometer.

\subsection{Statistical Analysis}

The data for all parameters were subjected to analysis of variance and the least significant difference was used to compare mean difference at $p<0.01$ [17] using Statistix software (version, 10.0, Tallahassee FL). Correlation coefficients were calculated and tested for significance at $p<0.01$ and $p<0.05$ [17] for the germination with total sugar content and starch content.

\section{Results}

In previous investigations of the same project to develop $F_{1}$ hybrids of vegetable corn with combinations of two genes controlling carbohydrate characters in $w x$ background, the table quality and chemical characters of the kernels at immature kernel stage and mature kernel stage were deliberately studied [12]. The results of a previous study showed a promising opportunity to develop premium-grade vegetable corn using the combinations of recessive genes [12].

\subsection{Seed Quality}

The traits related to seed quality including germination percentage, germination speed, seedling lengths of stem and root, and seedling dry weight were evaluated in 11 corn genotypes, including seven inbred lines and four $\mathrm{F}_{1}$ hybrids. Significant differences $(p \leq 0.01)$ among corn genotypes were observed for all traits related to seed quality in both BP test and AA test (Table 2). 
Table 2. Germination percentage, speed of seed germination, seedling length of root and stem and seedling dry weight under standard test between papers (BP test) and accelerated aging test (AA test).

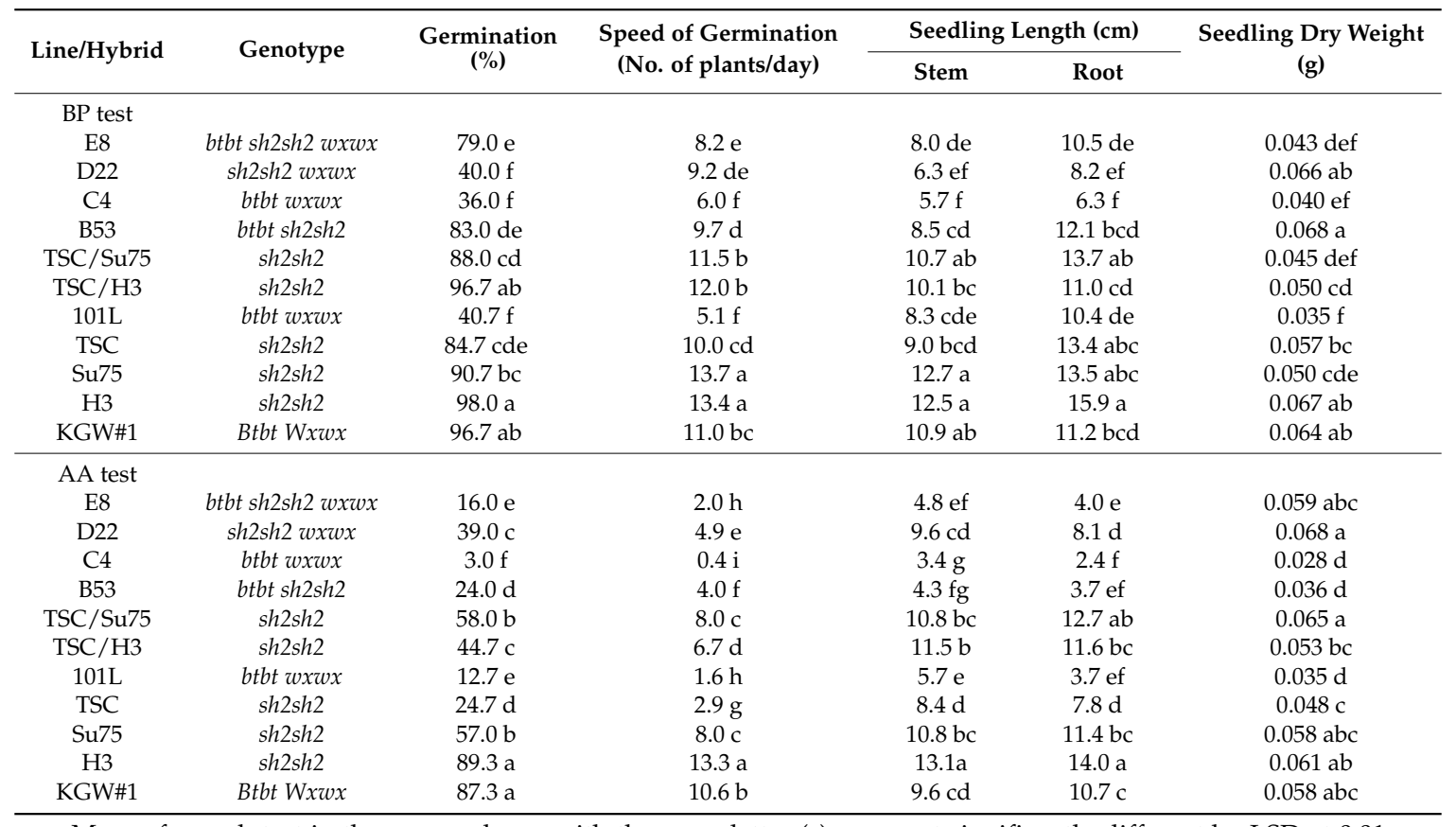

Means for each test in the same column with the same letter (s) were not significantly different by LSD at 0.01 probability level.

$\mathrm{BP}$ test had higher germination percentages than did AA test. For BP test, germination percentages ranged from $39.0 \%$ in $\mathrm{C} 4$ to $98.0 \%$ in $\mathrm{H} 3$, whereas, for AA-test, germination percentages ranged from $3.0 \%$ in $\mathrm{C} 4$ to $89.3 \%$ in $\mathrm{H} 3$. In general, hybrids performed better than did inbred lines for germination percentage except for B53, TSC/Su75 and TSC/H3, which were rather high similar to those of hybrids. These inbred lines are associated with sh2sh2 in TSC/Su75 and TSC/H3 or even sh2sh2 btbt in B53. The inbred lines that are associated with $w x w x$ (D22, C4 and 101L) generally had low germination percentage, ranging from $12.7 \%$ in $101 \mathrm{~L}$ to $40.0 \%$ in D22 in the BP test irrespective of the combined gene (either sh2sh2 or $b t b t)$. However, it is interesting to note here that E8 (btbt sh2sh2 wxwx) had a rather high germination percentage $(79.0 \%)$ although it has the combination of three recessive genes. After accelerated aging, most genotypes reduced germination percentage sharply except for $\mathrm{H} 3$ and KGW\#1, which could maintain high germination percentage (89.3\% for $\mathrm{H} 3$ and $87.3 \%$ for KGW\#1).

Germination speed followed the similar patterns of those for germination percentage in both $\mathrm{BP}$ test and AA test. In BP test, germination speed ranged from 6.0 seedlings per day in C4 to 13.7 seedlings per day in Su75, whereas, in AA test, germination speed ranged from 0.4 seedlings per day in $\mathrm{C} 4$ to 13.3 seedlings per day in $\mathrm{H} 3$. Again, hybrids were still better than inbred lines for germination speed, and the genotypes that could maintain high germination speed after accelerated aging were $\mathrm{H} 3$ (13.3 seedlings per day) and KGW\#1 (10.6 seedlings per day).

In the BP test, the single recessive genotypes TSC/Su75 $(s h 2 s h 2)$ had the longest seedlings $(10.7 \mathrm{~cm})$ and it was not significantly different from check varieties Su75 $(\operatorname{sh} 2 \operatorname{sh} 2)(12.7 \mathrm{~cm}), \mathrm{H} 3(\operatorname{sh} 2 \mathrm{sh} 2)(12.5 \mathrm{~cm})$, and KGW\#1 (Btbt Wxwx) $(10.9 \mathrm{~cm})$. E8 (btbt sh2sh2 wxwx) $(8.0 \mathrm{~cm})$ and B53 $(b t b t \operatorname{sh} 2 \mathrm{sh} 2)(8.5 \mathrm{~cm})$ were shorter than Su75 (sh2sh2), H3 (sh2sh2), and KGW\#1 (Btbt Wxwx), but they were still longer than the check varieties 101L (btbt wxwx) $(8.3 \mathrm{~cm})$ and D22 $(\operatorname{sh} 2 \operatorname{sh} 2 w x w x)(6.3 \mathrm{~cm})$, whereas C4 (btbt wxwx) $(5.7 \mathrm{~cm})$ was lowest.

In AA test, TSC/Su75 (sh2sh2) $(10.8 \mathrm{~cm})$ and TSC/H3 $(\operatorname{sh} 2 \mathrm{sh} 2)(11.5 \mathrm{~cm})$ had long seedlings but their seedlings were still shorter than those of check variety H3 $(13.1 \mathrm{~cm})$. Double recessive genotype D22 $(\operatorname{sh} 2 \operatorname{sh} 2 w x w x)(9.6 \mathrm{~cm})$ has long seedlings compared to other triple recessive genotype E8 (btbt $\operatorname{sh} 2 \operatorname{sh} 2 w x w x)(4.8 \mathrm{~cm})$ and double recessive genotypes, B53 (btb tsh2sh2) $(4.3 \mathrm{~cm})$, and C4 (btbt wxwx) 
$(3.4 \mathrm{~cm})$, and it was not significantly different from check varieties, Su75 (sh2sh2) $(10.8 \mathrm{~cm}), \mathrm{KGW \# 1}$ (Btbt Wxwx) $(9.6 \mathrm{~cm})$ and TSC $(\operatorname{sh} 2 \mathrm{sh} 2)(8.4 \mathrm{~cm})$.

In BP test, B53 (btbt sh2sh2) (0.068 g), and D22 (sh2sh2 wxwx) $(0.066 \mathrm{~g})$ had the highest seedling dry weight and they were not significantly different from check varieties, H3 (sh2sh2) $(0.067 \mathrm{~g})$ and KGW\#1 (Btbt Wxwx) (0.064 g). In AA test, D22 (sh2sh2 wxwx) (0.068 g), TSC/Su75 (sh2sh2) (0.065 g), and E8 (btbt sh2sh2 wxwx) (0.059 g) had the highest seedling dry weight and they were not significantly different from check varieties, Su75 (sh2sh2), H3 (sh2sh2), and KGW\#1 (Btbt Wxwx) (0.058 g, $0.061 \mathrm{~g}$, and $0.058 \mathrm{~g}$, respectively).

The complex processes and several factors such as genotype, environment, soil born disease and storage time are involved in seed germination and seed vigor [18]. In previous investigation, sweet corn with shrunken gene (sh2) had high sugar content in endosperm and low starch, and sweet corm of this type had low germination percentage and poor seedling vigor because the storage food in the seed are not sufficient for normal seed germination $[14,19,20]$. Low germination of sweet corn harvested at immature seed stage could be improved by seed priming [21].

Sweet corn varieties with shrunken gene had more rapid seed imbibitions and higher respiration rate during four days after imbibitions [3]. However, sweet corn varieties with more than one recessive gene controlling endosperm characters had lower germination than did the varieties with only one recessive gene. Although the new varieties with better seed germination than the parent $(101 \mathrm{~L}$ : btbt wxwx), which was developed previously, have been developed so far, these varieties had little contribution to germination increase.

Seed germination and seedling vigor are related to yield [22] and they are used as indicators for germination ability under field conditions. Harvest time [23] and storage are also the factors affecting seed germination and seedling vigor. It is difficult to determine the most appropriate time for harvest because of the variations in genotype, environment, and maturity index. Number of days after pollination and seed moisture content [24] were used as maturity indices for corn hybrids with shrunken gene (sh2). Using seed moisture content as an indicator for maturity had better seed germination and seedling vigor than did using number of days after pollination.

\subsection{Weights of Pericarp, Embryo, and Endosperm, Total Sugar Content, and Starch Content}

Corn kernels have three important parts that might be related to seed quality and table quality of sweet corn. Pericarp is the outer cover of the embryo and endosperm. Embryo is the seed part that will develop to be a new plant, and endosperm is the part for food reserved. Total sugar content and starch content indicate the types of food reserved, which directly affect seed quality and table quality of vegetable corn. As the seeds of the inbred lines for evaluation were not sufficient, the analysis of kernel properties could be carried without replication. However, the data were average from three values.

Endosperm constituted the largest portion of the kernel, ranging from $0.46 \mathrm{~g}$ in C4 to $2.00 \mathrm{~g}$ in KGW\#1 (Figure 2). Embryo was somewhat greater than pericarp but it was not always true in some genotypes, ranging from $0.08 \mathrm{~g}$ in E8 to $0.33 \mathrm{~g}$ in Su75 and H3. Pericarp was the smallest portion of the kernel, ranging from $0.11 \mathrm{~g}$ in TSC/Su75 to $0.21 \mathrm{~g}$ in B52. For visualization of the kernel proportions for each genotype, the data were also presented in Figure 2. Total sugar contents in general were higher than starch contents, ranging from $23.7 \mathrm{mg} / \mathrm{g}$ in KGW\#1 to $230.0 \mathrm{mg} / \mathrm{g}$ in C4, whereas starch content ranged from $36.1 \mathrm{mg} / \mathrm{g} 101 \mathrm{~L}$ in to $68.3 \mathrm{mg} / \mathrm{g}$ in C4. 

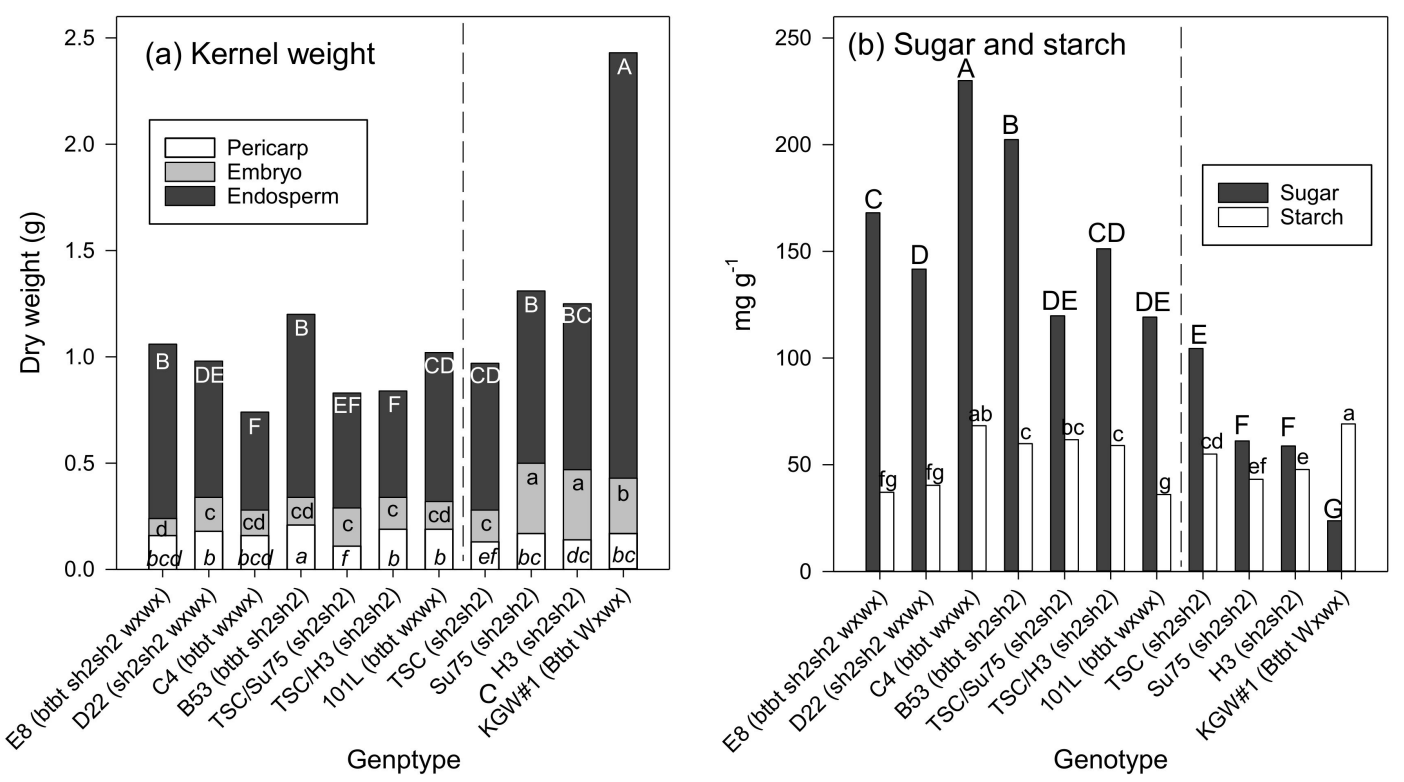

Figure 2. (a) Dry weight of pericarp, embryo and endosperm and (b) sugar content and starch content of 11 corn genotypes. Means for the same trait with the same letter are not significantly different at 0.01 probability level determined by LSD.

For kernel proportions, types of corn genotypes (hybrid or inbred) did not determine these proportions, but the differences in proportions were mainly dependent on corn genotypes. However, types of corn genotypes clearly determined total sugar content and starch content as inbred lines were generally greater than hybrids for these traits. For table quality, H3, TSC, and TSC/Su75 seemed interesting as they had the lowest pericarp, and C4 and B53 are the best genotypes for high total sugar content and high starch content.

Carbohydrate compositions and physiological process during seed development are dependent on genes controlling endosperm characters [25]. In this study, the inbred lines with shrunken gene $(s h 2)$ had intermediate starch content similar to those of the inbred lines with brittle gene $(b t)$ and waxy $(w x)$ gene and shrunken gene and waxy gene. Our results were in agreement with those reported previously [12].

In this study, starch content at seed maturity stage (30 days after pollination) slightly reduced compared to starch content at immature kernel stage (20 days after pollination). In the inbred line B73 of field corn, rapid increase in starch content occurred during pollination to 12 days after pollination and the starch content reached the highest value at 20-22 days after pollination, whereas the granule shape did not change. The number of starch granules did not increase during 23-30 days after pollination but starch granule shape did, forming more edges [26]. In sweet corn Shuxuan1, starch content gradually reduced after 18 days of pollination until 30 days after pollination [20]. Low starch content in sweet corn varieties with shrunken or brittle gene was due to low synthesis of starch during seed development and the high accumulation of sugar [27].

In this study, small change in starch content was observed between starch contents at immature kernel stage and maturity stage. The low reduction in starch content in sweet corn varieties with shrunken gene was due to the reduction in amylase activity in aleurone layer, resulting in the inhibition of starch breakdown during germination [28].

In the earlier work of our project, the inbred line101bt (btbt wxwwx) and the inbred line $216 \mathrm{sh} 2$ $(\operatorname{sh} 2 \operatorname{sh} 2 w x w x)$ had the highest sugar contents of 112.9 and $115 \mathrm{~mL} /$ gram fresh weight, respectively. However, the newly-developed sweet corn inbred lines, C4 (btbt wxwx) and D22 (sh2sh2 wxwx), had the highest sugar contents of 220.8 and $165.4 \mathrm{~mL}$ /gram fresh weight, which were much higher than those of the old inbred lines although they had the same genotypes [12]. The earlier study showed that it is 
possible to develop the sweet corn inbred lines that had higher table quality by using the combinations of genes controlling endosperm characters.

In general, sugar content at immature kernel stage was higher than at mature kernel stage. However, the reductions in sugar content varied depending on genotype. The carbohydrate compositions in endosperm of sweet corn and other types of corn have been studied [2,29]. Sugar content increased from pollination and peaked at 15-20 days after pollination. After the endosperm sugar reached the highest content, the sugar content gradually reduced until it was lowest at physiological maturity stage. In our earlier work in 6 inbred lines of waxy corn, sugar contents were highest during 15-19 days after pollination, and they gradually reduced during 20-40 days after pollination [30]. The soluble sugar gradually conversed to starch and accumulated in endosperm during seed development (14-42 days after pollination) [20].

\subsection{Correlations among Traits Related to Seed Quality and Carbohydrate Characters}

Most traits related to seed quality were inter-related except for seedling dry weight, which has low correlation with germination percentage determined by BP test, germination speed determined by $\mathrm{BP}$ test, germination percentage determined by AA test and germination speed determined by AA test (Table 3). The correlations among these traits were better in AA test than BP test as all correlation coefficients were significant, ranging from $0.63 *$ between seedling dry weight and germination speed to $0.99^{* *}$ between germination speed and germination percentage. However, when both methods are considered, germination percentage, germination speed, stem length and root length were inter-related and correlation coefficients ranged from $0.74 * *$ between root length and germination speed using the $\mathrm{BP}$ test to $0.99^{* *}$ between germination speed and germination percentage using the AA test.

Table 3. Correlation among germination parameters with total sugars and starch contents under BP test and AA test ( $n=$ seven inbred lines and four hybrids).

\begin{tabular}{|c|c|c|c|c|}
\hline \multirow[b]{2}{*}{ Parameters } & \multicolumn{2}{|c|}{ BP Test } & \multicolumn{2}{|c|}{ AA Test } \\
\hline & Germination & $\begin{array}{c}\text { Speed of } \\
\text { Germination }\end{array}$ & Germination & $\begin{array}{c}\text { Speed of } \\
\text { Germination }\end{array}$ \\
\hline Speed of germination & $0.83 * *$ & & $0.99 * *$ & \\
\hline Stem length & $0.83^{* *}$ & $0.84^{* *}$ & $0.83^{* *}$ & $0.85^{* *}$ \\
\hline Root length & $0.79^{* *}$ & $0.74^{* *}$ & $0.88^{* *}$ & $0.90^{* *}$ \\
\hline Seedling dry weight & 0.39 & 0.53 & $0.66^{*}$ & $0.63 *$ \\
\hline Pericarp wt. & -0.24 & -0.28 & -0.28 & -0.27 \\
\hline Embryo wt. & 0.50 & $0.75^{* *}$ & $0.85^{* *}$ & $0.86^{* *}$ \\
\hline Endosperm wt. & 0.36 & 0.18 & 0.53 & 0.43 \\
\hline Total sugar & -0.52 & -0.59 & $-0.82 * *$ & $-0.76^{* *}$ \\
\hline Total starch & 0.26 & 0.13 & 0.19 & 0.17 \\
\hline
\end{tabular}

* Correlation is significant at the 0.05 level. ${ }^{* *}$ Correlation is significant at the 0.01 level.

For the relationships between seed quality traits with kernel characters and carbohydrate characters, pericarp weight, endosperm weight and starch content were not significantly correlated with all traits related to seed quality (Table 4), whereas embryo weight and total sugar content were significantly correlated with all traits related to seed quality especially for AA test. Embryo weight was positively and significantly correlated with germination percentage and germination speed in AA test, whereas total sugar content was negatively and significantly correlated with germination percentage and germination speed in AA test. 
Table 4. Correlation among germination parameters with total sugars and starch contents under BP test and AA test ( $n=$ seven inbred lines and four hybrids).

\begin{tabular}{ccccc}
\hline & BP Test & \multicolumn{3}{c}{ AA Test } \\
\hline Parameters & Germination & $\begin{array}{c}\text { Speed of } \\
\text { Germination }\end{array}$ & Germination & $\begin{array}{c}\text { Speed of } \\
\text { Germination }\end{array}$ \\
\hline Speed of germination & $0.83^{* *}$ & $0.84^{* *}$ & $0.99^{* *}$ & $0.83^{* *}$ \\
Stem length & $0.83^{* *}$ & $0.74^{* *}$ & $0.88^{* *}$ & $0.85^{* *}$ \\
Root length & $0.79^{* *}$ & 0.53 & $0.66^{*}$ & $0.90^{* *}$ \\
Seedling dry weight & 0.39 & -0.28 & -0.28 & $0.63^{*}$ \\
Pericarp wt. & -0.24 & $0.75^{* *}$ & $0.85^{* *}$ & -0.27 \\
Embryo wt. & 0.50 & 0.18 & 0.53 & $0.86^{* *}$ \\
Endosperm wt. & 0.36 & -0.59 & $-0.82^{* *}$ & $-0.76^{* *}$ \\
Total sugar & -0.52 & 0.13 & 0.19 & 0.17 \\
Total starch & 0.26 & &
\end{tabular}

${ }^{*}$ Correlation is significant at the 0.05 level. ${ }^{* *}$ Correlation is significant at the 0.01 level.

Therefore, selection of corn genotypes with larger embryo might improve seed quality, and $\mathrm{H} 3$ $(0.33 \mathrm{~g})$ and Su75 $(0.33 \mathrm{~g})$ are promising for this traits. As pericarp was not correlated with all traits related to seed quality, selection of genotypes with low pericarp is highly recommended for improved table quality, and TSC /Su75 (0.11 g), TSC (0.13 g), and H3 (0.14 g) are worth selecting.

In this study, seed quality parameters such as germination speed, germination percentage, stem length, root length, and seedling dry weight were related to each other and the correlations after accelerated aging were somewhat higher than those of newly-harvested seeds. In previous studies in corn, accelerated aging reduced shoot length, root length, germination percentage, and germination speed $[21,31]$. The results in this study supported previous findings. Germination percentage under laboratory conditions could be used for production of germination percentage under field condition as this parameter evaluated under laboratory condition was positively and significantly correlated with that evaluated under field condition [18]. Germination speed also had the similar pattern of germination percentage as they had positive and significant correlation both under BP test and AA test [32]. These findings imply that the seed with high seedling vigor has high germination speed. In corn germination percentage of newly harvested seeds was closely related with germination percentage of accelerated aged seeds [33].

Food in the endosperm was another factor affecting germination process of seeds [34] as seeds require a source of energy for growth [5]. In this study, sugar had a detrimental effect on seed germination. Germination percentage under field condition was negatively correlated with sugar content in dry seeds [35].

However, total starch and total sugar alone are not sufficient to predict seed germination and seedling vigor as several factors such as genotype, soil born disease, environmental factor, seed storage [18], seed weight, and seed coat [19], all have an effect.

\subsection{Application in Seed Production}

The newly developed inbred lines with combinations of two and three genes have relatively low germination percentage and seedling vigor. If the inbred lines are to be adopted in hybrid seed production, it is highly recommended to germinate the seeds in seedling nursery using plug trays and transfer the seedlings to the fields at appropriate growth stage (usually not more than 15 days). These inbred lines should be evaluated for combining ability of seed quality in order to select the best parents for hybrid seed production. The information obtained in this study is useful for sweet corn breeding to improve table quality of sweet corn. 


\section{Conclusions}

The inbred lines (TSC/Su75 and TSC/H3; $\mathrm{F}_{6}$ generation) with single recessive gene (sh2sh2) had the highest germination percentage and seedling vigor compared with the inbred lines with two recessive genes (sh2sh $2 w x w x, b t b t w x w x$, and $b t b t \operatorname{sh} 2 s h 2)$ and three recessive genes (btbt sh2sh2 $w x w x)$. D22, C4, B53, and B10 had reasonably good germination percentage under favorable conditions, but these inbred lines had poor germination percentages after accelerated aging. After accelerated aging, the inbred lines with combination of one gene (sh2sh2) had the highest seedling vigor. The inbred lines had poor seedling vigor when sh2sh2 was combined with btbt and wxwx. D22 and B10 had the highest sugar content at immature kernel stage, whereas $C 4$ had the highest starch content at the immature kernel stage and B53 had the highest starch content at the mature kernel stage.

Author Contributions: Conceptualization: P.P., D.J., D.K., S.S., K.L., and B.S.; formal analysis: P.P., and B.S.; methodology: P.P., S.S., and B.S.; writing-original draft: P.P. and B.S.; writing-review and editing: D.J., D.K., S.S., and K.L.

Funding: The Thailand Research Fund (project no. RTA 5880003 and project code: IRG5780003).

Acknowledgments: The Thailand Research Fund (TRF) is acknowledged for providing financial support through the Senior Research Scholar Project of Sanun Jogloy (project no. RTA 5880003). Acknowledgment is extended to the Thailand Research Fund (project code: IRG5780003), Khon Kaen University (KKU) and the Faculty of Agriculture KKU for providing financial support for manuscript preparation activities.

Conflicts of Interest: The authors declare no conflict of interest. The funding sponsors had no role in the design of the study; in the collection, analyses, or interpretation of data; in the writing of the manuscript; or in the decision to publish the results.

\section{References}

1. Lertrat, K.; Pulam, T. Breeding for increased sweetness in sweet corn. Int. J. Plant Breed. 2017, 1, 27-30.

2. Creech, R.G. Genetic control of carbohydrate synthesis in maize endosperm. Genetics 1965, 52, 1175-1186. [PubMed]

3. Styer, R.C.; Cantliffe, D.J.; Hannah, L.C. Differential seed and seedling vigor in shrunken-2 compared to three other genotypes of corn at various stages of development. J. Am. Soc. Hortic. Sci. 1980, 105, 329-332.

4. Tracy, W.F. Sweet corn. In Specialty Corns, 2nd ed; Hallauer, A.R., Ed.; CRC: Boca Raton, FL, USA, 2001; pp. 155-198.

5. Styer, R.C.; Cantliffe, D.J. Dependence of seed vigor during germination on carbohydrate source in endosperm mutants of maize. Plant Physiol. 1984, 76, 196-200. [CrossRef] [PubMed]

6. Callan, N.W.; Mathre, D.E.; Miller, J.B. Bio-priming seed treatment for biological control of Pythium ultimum pre-emergence damping-off in sh2 sweet corn. Plant Dis. 1990, 74, 368-372. [CrossRef]

7. Parera, C.A.; Cantliffe, D.J. Presowing seed treatments to enhance supersweet corn seed and seedling quality. HortScience 1994, 29, 277-278.

8. Tracy, W.F. History, genetics, and breeding of supersweet (shrunken2) sweet corn. Plant Breed. Rev. 1997, 14, 189-236.

9. Ordas, B.; Revilla, P.; Ordas, A.; Malvar, R.A. Hybrids sugary x sugary enhancer of sweet corn: A valuable option for cool environments. Sci. Hort. 2008, 118, 111-114. [CrossRef]

10. Lertrat, K.; Thongnarin, N. Novel approach to eating quality improvement in local waxy corn: Improvement of sweet taste in local waxy corn variety with mixed kernels from super sweet corn. Acta Hoertic. 2008, 769, 145-150. [CrossRef]

11. Carey, E.E.; Dickinson, D.B.; Rhodes, A.M. Sugar characteristics of sweet corn populations from a sugary enhancer breeding program. Euphytica 1984, 33, 609-622. [CrossRef]

12. Available online: https://www.maizegdb.org (accessed on 6 December 2018).

13. Simla, S.; Lertrat, K.; Suriharn, B. Combinations of multiple genes controlling endosperm characters in relation to maximum eating quality of vegetable waxy corn. SABRAO J. Breed. Genet. 2016, 48, 210-218.

14. Borowski, A.M.; Fritz, V.A.; Waters, L. Seed maturity influences germination and vigor of two shrunken-2 sweet corn hybrids. J. Am. Soc. Hortic. Sci. 1991, 116, 401-404. 
15. Ketthaisong, D.; Suriharn, B.; Tangwongchai, R.; Lertrat, K. Changes in physicochemical properties of waxy corn starches at different stages of harvesting. Carbohydr. Polym. 2013, 98, 241-248. [CrossRef] [PubMed]

16. Dubois, M.; Gilles, K.A.; Hamilton, J.K.; Rebers, P.A.; Smith, F. Colorimetric method for determination of sugar and related substance. Anal. Chem. 1956, 2, 350-356. [CrossRef]

17. Gomaz, K.A.; Gomez, A.A. Statistical Procedures for Agricultural Research, 2nd ed.; John Wiley and Sons: New York, NY, USA, 1984; p. 680.

18. Parera, C.A.; Cantliffe, D.J.; Rtoffella, P.J.; Scully, B.T. Field emergence of shrunken-2 corn predicted by singleand multiple-vigor laboratory. J. Am. Soc. Hortic. Sci. 1995, 120, 128-132.

19. Adetimirin, V.O.; Kim, S.K.; Szczech, M. Factors associated with emergence of shrunken-2 maize in Korea. J. Agric. Sci. 2006, 144, 63-68. [CrossRef]

20. Cao, D.D.; Hu, J.; Huang, X.X.; Wang, X.J.; Guan, Y.J.; Wang, Z.F. Relationship between changes of kernel nutritive components and seed vigor during development stages of F1 seeds of sh2 sweet corn. J. Zhejiang Univ. Sci. B 2008, 9, 964-968. [CrossRef]

21. Simla, S.; Lertrat, K.; Suriharn, B. Gene effects of sugar compositions in waxy corn. Asian J. Plant Sci. 2009, 8, 417-424.

22. Vitor, H.V.M.; Silvio, M.C.; Durval, D.N.; Tulio, L.P.; Marcos, A.N.D. Effects of seed vigor on intra-specific competition and grain yield in maize. Agron. J. 2012, 105, 222-228.

23. Liu, J.B.; Fu, Z.Y.; Xie, H.L.; Hu, Y.M.; Liu, Z.H.; Duan, L.J.; Xu, S.Z.; Tang, J.H. Identification of QTLs for maize seed vigor at three stages of seed maturity using a RIL population. Euphytica 2011, 178, 127-135.

24. Churchill, G.A.; Andrew, R.H. Effect of two maize endosperm mutants on kernel maturity, carbohydrates, and germination. Crop Sci. 1984, 24, 76-81. [CrossRef]

25. Boyer, C.D.; Shannon, J.C. The use of the endosperm genes for sweet corn improvement. Plant Breed. Rev. 1984, 1, 139-161.

26. Li, L.; Blanco, M.; Jane, J. Physicochemical properties of endosperm and pericarp starches during maize development. Carbohydr. Polym. 2007, 67, 630-639. [CrossRef]

27. Boyer, C.D.; Hannah, L.C. Kernel mutants of corn. In Specialty Corns, 2nd ed.; Hallauer, A.R., Ed.; CRC press: New York, NY, USA; Washington, DC, USA, 2001; pp. 1-31.

28. Sanwo, M.M.; DeMason, D.A. Characteristics of -amylase during germination of two high-sugar sweet cultivars of Zea mays L. Plant Physiol. 1992, 99, 1184-1192. [CrossRef]

29. Xu, J.G.; Hu, Q.P.; Wang, X.D.; Luo, J.Y.; Liu, Y.; Tain, C.R. Changes in the main nutrients, phytochemicals and antioxidant activity in yellow corn grain during maturation. J. Agric. Food Chem. 2010, 58, 5751-5756. [CrossRef] [PubMed]

30. Simla, S.; Lertrat, K.; Suriharn, B. Carbohydrate characters of six vegetable waxy corn varieties as affected by harvest time and storage duration. Asian J. Plant Sci. 2010, 9, 463-470. [CrossRef]

31. Vashisth, A.; Nagarajan, S. Germination characteristics of seeds of maize (Zea mays L.) exposed to magnetic fields under accelerated aging condition. Int. Agrophys. 2009, 9, 50-58.

32. Shah, F.S.; Watson, C.E.; Cabrera, E.R. Seed vigor testing of subtropical corn hybrids. MAFES 2002, 23, 1-5.

33. Noli, E.; Casarini, E.; Urso, G.; Conti, S. Suitability of three vigour test procedures to predict field performance of early sown maize seed. Seed Sci. Technol. 2008, 36, 168-176. [CrossRef]

34. Wann, E.V. Seed vigor and respiration of maize kernels with different endosperm genotypes. J. Am. Soc. Hortic. Sci. 1980, 105, 31-34.

35. Azanza, V.; Zur, A.B.; Juvik, J.A. Variation in sweet corn kernel characteristics associated with stand establishment and eating quality. Euphytica 1996, 87, 7-18. [CrossRef]

(C) 2018 by the authors. Licensee MDPI, Basel, Switzerland. This article is an open access article distributed under the terms and conditions of the Creative Commons Attribution (CC BY) license (http://creativecommons.org/licenses/by/4.0/). 